\title{
Rethinking Adult Literacy in the Contex of Oral Culture
}

\begin{abstract}
Ahmet YILDIZ
ABSTRACT. The article focused on potential effects of oral culture studies on the field of education/adult literacy. The oral tradition, which is prevalent among Turkish society, has influence on educational area. Because oral culture studies focus on learners' life experiences, oral culture studies contribute learning atmosphere, educational materials, program participation, and learner evaluation in the context of adult literacy.
\end{abstract}

Key Words: Oral culture, education, adult literacy.

\section{SUMMARY}

Many findings of the researches on oral culture can be mentioned that they can supply expansion to the continuing debates on the field of education. In this article, the possible contribution of the oral culture studies to the field of adult educationespecially in the context of adult literacy- will be discussed under the headlines of learning atmosphere and educative materials, program, participation to the program, teaching methods, assessment of the teachers and the learners.

Oral culture is the name of the culture which does not know the scripture, where the communication is realized through talking and where the primary relations are dominant. It is significant to make a distinction between the oral tradition and the written communication in the societies where scripture is used. Because the oral communication in the societies that have scripture is not the same with communication in the societies which does not have scripture (Goody, 1989). In the societies which do not have scripture, oral culture must carry the whole burden of the cultural transfusion. Though, in the literate societies where the scripture is in circulation, oral culture undertakes only a small part of the standardized verbal patterns and literacy activities.

* Dr., Ankara University, Faculty of Educational Sciences 
It is possible to state that Turkish society is surrounded by oral culture in many fields from political to religious life, from entartainment to sport. In this sense, the analysises of oral culture present significant data about the perception of the society relating to school and learning in conjunction with participation. As it is known, in Turkey society, especially in places where the density of traditional bond networks continues, many non-literate adults have been thinking that taking lessons in class environment will humiliate themselves; in other words, taking their rights of being adult, the class will make them child and think that only the children take lesson in school. This way of thinking apparantly reflects the viewpoint of the cultural environment in which the person takes place about education. Such perception is seen frequently in the social segments where the traditional bonds continue and oral culture is still alive. Because, in oral cultures, as in pre-modern societies, learning environments in school form is perceived as for the children. Further more, adult learning be formed not in this types of classroom with formal learning, but be formed in their daily lives.

In the attempts of literacy, the life experiences of target group and how they perceive these experiences can constitute a suitable starting point for the program. Learners participate to the learning environments with a specific experience. Ignoring this accumulation can cause serious problems especially for the adult learning. From the aspect of social segments perpetuating oral culture, two main impacts of the assessment of this accumulation in learning environments can be mentioned: Firstly, in oral cultures, knowledge is close to human life and instead of being abstract, it is related to situation. Therefore, it is essential for the learning process to relate the content of education with the life of the learner. It should be emphasized that taking the experiences of the learners into account constitutes the most important part of establishing a rich learning environment. The second one is related to ego perception. In other words, if the learners are assumed as "empty" in terms of accumulation/ experience, learning environment has an atmospehere excluding the learners. Assessed from this aspect, oral culture products, that exists in the socio-cultural environment where the program will be organized, can constitute a genuine resource of information about the participators' beliefs, values and behaviour patterns.

The reality of oral culture shows itself in many other fields of education. When the education problems are uttered; the "recitative method in education" which place in the front seats of problems scale, is the most significant reflection of oral culture towards the education.

In this sense, the most important contribution presented by oral culture analyses to the field of adult education, specifically for the studies of the adult literacy is that they have provided detailed portraits about the the sociocultural context where the learning is realized. In this circumstance, the studies of oral culture invites the educational scientists to approach the educative process with the factors effecting education that are out of school/class. 


\title{
Sözlü Kültür Bağlamında Yetişkin Okuryazarlığını Yeniden Düşünmek
}

\begin{abstract}
Ahmet YILDIZ
ÖZ. Bu makalede, sözlü kültür incelemelerinin eğitim/yetişkin okuryazarlığ 1 alanına sunabileceği olası açılımlar ele alınmaktadır. Türkiye toplumunda canlılığını sürdüren sözlü gelenek, eğitime ilişkin pek çok sorunda kendisini hissettirmektedir. $\mathrm{Bu}$ anlamda sözlü kültür çalışmaları, öğrenenlerin yaşam deneyimlerine odaklanması nedeniyle, eğitim alanına -özellikle yetişkin okuryazarlığı bağlamındaögrenme atmosferi ve eğitsel materyaller, programlara katılım, öğretim yöntemleri ve öğrenilenlerin/öğrenenlerin değerlendirilmesi konularında katkı sunmaktadır.
\end{abstract}

Anahtar Sözcükler: Sözlü kültür, Eğitim, Yetişkin okuryazarlığı.

\section{Gİiş̧}

Batı ile diğer kültürlerin farkının yazıyı içselleştirmiş toplumlarla sözlü kültürü yaşatan toplumlar arasındaki farka indirgenmesi ve Göka (1999: 163)'nın Tannen (1980)'den aktardığı "asırlardır yazı yazmasını bilmelerine rağmen, henüz yazıyı içselleştirmemiş Arap, Yunan ve diğer Akdeniz kültürleri, sözlü kültürün kalıplaşmış düşünce ve anlatım biçimlerine hala sıkı sıkıya bağlıdır" saptaması eğitim bilimleri ve özellikle de yetişkin eğitimi çalışmaları için görmezden gelinemeyecek kadar önemlidir. Bu tartışmalar özellikle yetişkin öğrenmesinin sosyo-kültürel boyutları ve öğrenmenin yöntem ve uygulamalarının altında yatan anlam ve koşullara ilişkin önemli açılımlar sağlayacak niteliktedir.

Sözlü ve yazlı kültür arasındaki ayrım, son zamanlarda dilin sözlü niteliğinin ve sözlü kültürle yazılı kültür arasındaki farklılıkların anlaşılmasıyla birlikte, bazı araştırmacılar tarafından önerilmeye başlanmıştır. Sözü edilen kavramsallaştırma bazı soruları beraberinde getirse de bilim dünyasında "söz" ve "yazı" arasında,

\footnotetext{
Dr. , Ankara Üniversitesi, Eğitim Bilimleri Fakültesi.
} 
dolayısıyla "sözlü" ve "yazılı kültür"ler arasında paradigmatik düzeyde farklılıklar olduğu kabul edilmektedir (Göka, 1999: 162). Genel olarak bu görüşler yazının toplumsal yaşamdaki dönüştürücü etkisini esas almaktadır. Şöyle ki, yazının sözü dondurması ve görünür kılması, "dilden yararlanma organı olarak kulaktan göze doğru bir kaymayı" temsil eder (Postman, 1994). Böylece yazı, görsel olmayan "uzay ve duyuların görsel bir çerçeve içine alınmasını" sağlamıştır. O halde yazı, "alışılagelmiş duyusal etkileşimden görsel duyunun bir soyutlanışı"dır (Mcluhan, 1999). Ayrıca yazı, konuşmaya sadece bir ek değildir, "konuşmayı sözlü-işitsel duyudan çıkarıp yeni bir duyu dünyasına, görmeye bağladığı" için hem konuşmayı hem de düşünme biçimini dönüştürür (Ong, 1999). Bu süreç, konuşmanın kaydedilmesi, bir yere dökülmesi, insanoğluna sözcükleri açı bir biçimde ayırma, sözcük sistemleri oluşturma ve kıyasa dayalı akıl yürütme olanağını sağlamıştır (Goody, 2001).

Goody (1989) de yazının kullanıldığı toplumlardaki sözlü gelenek ve yazılı iletişim arasında ayrım yapmanın önemine işaret eder. Çünkü yazının bulunduğu toplumlardaki sözlü iletişim, yazıya sahip olmayan toplumlardaki iletişimle aynı değildir. Yazıya sahip olmayan toplumlarda sözlü gelenek, kültürel aktarımın tüm yükünü taşımak zorundadır. Oysa yazının dolaşımda olduğu okuryazar toplumlarda sözlü gelenek, standardize edilmiş sözel biçimlerin ve okuryazarlık faaliyetlerinin yalnızca küçük bir parçasını üstlenir.

\section{Türkiye’de Sözlü Kültür}

Yazı üzerinden yapılan bu ayrımda sözlü kültür, yazıyı bilmeyen, iletişimin konuşma ile sağlandığı ve birincil ilişkilerin hakim olduğu kültürün adıdır. Yazının varolmasına karşın sözlü geleneği canlı bir şekilde sürdüren toplumlarda da sözlü hareket tarzı hakim olabilir. Buna Ong "sözlü hareket eden" anlamına gelen "verbomotor" yaşam biçimi adını verir (1999: 86-87):

\footnotetext{
Teknoloji devri insanı sözlü hareket eden (verbomotor) deyimiyle nitelendirdiğimiz kültürlerin konuşmaya gereğinden fazla önem verdiğini ve hitabet sanatını aşırı derecede kullandığını ileri sürebilir. Birincil sözlü kültürde ticaret bile, parasal bir işlemden önce, esasen güzel söz söyleme, hitabet sanatıdır. Ortadoğu çarşılarında alışveriş yapmak, süpermarkette yapılan alışverişe, ileri kültür insanının bedelini ödemekle noktaladığını sandığ basit alışverişe benzemez: Her şeyden önce bir dizi kelime ve beden dilini devreye sokan, bol manevralı ve ölçülü bir düello, zeka yarışı, sözlü üstünlük yarışıdır.
}

$\mathrm{Bu}$ betimleme sanki Türkiye çarşılarını anlatmaktadır. Türkiye'nin geleneksel çarşılarında benzer ritüeller ve kalıpsal ifadeler halen gözlenebilir bir gerçekliktir. Örneğin, Kayaoğlu (1998:305) yaklaşık 500 yıldır İstanbul Beyazıt'ta faaliyet sürdüren hurdacı, bakırcı ve antikacı esnafin alışveriş sırasında kullandıkları atasözü, atasözü nitelikleri taşıyan söz kümeleri, deyimler, terimler ve kalıp sözlerden çok sayıda toplayarak sözlü kültürün çarşıllardaki canlığını göstermiş̧ir. 
Denilebilir ki, Türkiye'de sözlü kültüre en yoğun şekilde, gelenekselin yaşandığı yerlerde ve bu yerlerde sürdürülen ritüellerde rastlanmaktadır: gündelik yaşamda sıklıkla kullanılan deyişler, çarşılarda, pazarlarda satıcıların mallarını satmak için yüksek sesle bağırmaları ve kalıpsal ifadeleri, aynı şekilde otobüs ve minibüs terminallerinde bir biriyle yarış edercesine seslenmeler; "sıra gecesi”" olarak isimlendirilen eğlenceler ve sazlı-sözlü "taşlama", "atışma" geleneğinin sürmesi; en sıradan ev ziyaretinde bile selamlaşma ve hal hatır sorma faslının uzunluğu ve biçimselliği. Kalıpsal ifadeler gelenekselin dışında da kendini yoğun bir biçimde hissettirir. Hemen hemen her dolmuş ya da kamyonda yazılı olan "özlü sözler”; yeni türkü/şarkılarda bile anlamsızlık boyutuna varan kafiyenin bu denli yaygın olması; mektuplarda ve hatıra defterlerinde sıklıkla kullanılan kalıplar bunun yaygın göstergeleridir.

Sözlü kültür ürünlerinden olan kalıplaşmış halk inanışları, aşık tarzı kültür geleneği (Çobanoğlu, 2003) ve yaygın atasözü kullanımı Türkiye toplumunda, özellikle kırsal bölgelerde son derece yaygındır. Pierce (2003:174) de Türk halk kültüründeki bu zenginlikleri vurgulamıştır. Anadolu'da bir köyde antropolojik bir araștırma yapan Pierce, köyde öykülerin önemine değinerek, onları üçe ayırmıştır: (1) Hoca öyküleri, (2) Keloğlan masalları, (3) diğerleri. Çobanoğlu (2003) tarafından "yaşanmış olağanüstü tecrübelerin hikâyesi" olarak tanımlanan "memorat"lar da Türkiye toplumunun sözlü kültür ürünleri arasında en yaygın olanlarından biridir. Daha çok "hurafe ya da batıl inanç" biçiminde değerlendirilen bu öyküleri inceleyen Çobanoğlu (2003) kültürün içindeki memoratları tematik olarak sınıflandırmaya çalışmıştır: Hızır, cinler, alkarısı, enkebit, ağırlık basmasıkarabasan, Çarşamba karısı, çıtlık kuşu, demirkıynak, yol azdıran, ölüler, büyü, nazar, fal ve modern kent memoratları olarak ruh çağırma, astral yolculuk, reerkarnasyon ve UFO'larla kurulan iletişim gibi.

Sözlü kültür ürünleri geleneksel olarak "kırsal kesimin elektrik ve dolayısıyla radyo ve özelikle televizyon gibi eğlence araçlarına sahip olmadığı dönemlerde genellikle geceleri "misafirlik" gibi sosyal etkinliklerin bir parçası" olarak (Çobanoğlu, 2003) anlatılmaktaydı. Özellikle kırsal kesimde günümüzde de bir ölçüde varlığını sürdüren bu tür aktarımlar, sözlü kültür ortamının masal, bilmece, efsane, türkü ve benzeri türlerinin yaşandığ 1 bir "sohbet” ortamıdır. Günümüzde de kentlerde kadınlar arasında "gün yapma" olarak adlandırılan pratiklerde, erkeklerin kahvehane sohbetlerinde, yazlıklarda akşamları gençler arasında, öğrenci kamplarında özellikle gece kamp ateşi etrafında ya da birçok yerde elektrikler kesildiğinde memorat ve efsanelerin anlatıldığı bilinmektedir (Çobanoğlu, 2003). Daha çok kırsal yaşamda görülen memorat ya da efsane gibi sözlü kültür ürünleri modern kent yaşamına da sızmıştır. Yazılı ve görsel medya bu eğilimi "sırlar dünyası" gibi programlarla ya da UFO haberleri gibi yayınlarla veya fal sayfalarıyla desteklemektedir. Tüm bunlar, Göka'nın da (1999) işaret ettiği gibi, Türkiye toplumunun, "söz" ve "yazı" arasında kalakalmış bir "verbomotor geçiş kültürü" özelliklerini taşıdığını göstermektedir. 
Türkiye toplumunun, siyasal yaşamdan dinsel yaşama, eğlenceden spora kadar pek çok alanda sözlü kültür tarafindan kuşatıldığını gösteren bu tür örnekleri artırmak mümkündür. Ancak konu açısından önemli olan, bu kuşatılmışlık durumunun eğitim alanı açısından ne ifade ettiğidir. Eğitimdeki ezber oranının yüksekliğinden, en soyut alanlardan biri olan matematiğin öğrenilmesindeki güçlüklere, kalıplaşmış ifade kullanımının yoğunluğundan eğitime dair toplumsal algiya, okuma-yazma becerisinin gerilemesi ya da tamamen unutulmasina kadar birçok konu, sözlü kültürün eğitim ortamlarında da kendini hissettirdiğini göstermektedir. Aynı şekilde sözlü kültür, yetişkin okuryazarlığı etkinlikleri için de görmezden gelinemeyecek kadar önemli bir olgudur.

\section{Eğitim, Sözlü Kültür ve İktidar}

Okuryazar olmak, toplum tarafindan önem atfedilen bilgilerin şifrelenme süreçlerine ilişkin bir egemenliğe göndermede bulunur. Okuma yazma bilmeyenlerin ya da eğitim olanaklarından düşük düzeyde yararlananların çoğu kez alt sosyo-ekonomik düzeydeki topluluklardan olması bu yüzden tesadüf değildir. Egemen sınıfın egemenlik kurma ve sürdürme pratikleri içinde yazının kilit konumu göz ardı edilemez. Yazı ve yazıya dayalı teknoloji kullanma becerisi ile okuryazarlık oranının ve eğitim düzeyinin ülkelerin temel gelişmişlik göstergeleri olarak sayılması söz konusu ilişkiyi açıkça göstermektedir. Esasen, yazıyı hiç kullanmayan ya da sınırlı düzeyde kullanan sözlü kültür, çoğunlukla bu egemenlik ilişkileri içinde egemen olmayanların kültürünü yansitır. Bu anlamda, Köker'in (2005: 13) de ifade ettiği gibi, sözlü kültür, bir yanıyla insanlığın uzun geçmişinin izi zor sürülebilecek deneyimlerinin ve eylemlerinin bilgisini içerirken, diğer yandan yazıyla belgelenen ve görsellikle biçimlenen modern zamanların egemen olmayan katman, kesim ve sınıflarının dayanışmalarını güçlendiren deneyimlerine dayanmaktadır.

Bağımlı katman ve sınıfların deneyimleri ile eğitim pratiklerinde yaşanan uyumsuzluk eğitimin tarafsızlığı konusunu gündeme taşımaktadır. Bir eğitim sistemi bütün öğrenenlere, eşit firsatlar sağlama yanlısı olsa ve en yüksek toplumsal akışkanlığı garanti etse bile, okul sisteminin dışında, aile ve toplumsal ortam tarafından aktarılan genel kültürdeki eşitsizliklere bağlı olarak, sınırlı bir demokratik etki yaratır (Amin, 1997). Bernstein'ın da (1990) belirttiği gibi, "okulda okutulan yazılı metinler bazı yönlerden okul dışındaki sözlü anlatılardan” farklıdırlar. Yasal ve egemen pedagojik pratiğin temsilcisi olan okul tarafindan öğrencilere okutulan yazılı metinler ile okul dışındaki pedagojik yönelimli kurum veya kuruluşlar tarafindan sunulan metinler arasında önemli farklılıklar vardır: Yerel ve somut olana ilişkin bağlam bağımlı (context-dependent) anlamlar ile yerel olmayan ve soyuta ilişkin bağlam-bağımsız (context independent) anlamlar arasındaki farklılık ve ilişki. Daha somut ifade etmek gerekirse bu farklılık, somut veya bağlam-bağımlı bilişsel işlemler ile soyut veya bağlam-bağımsız bilişsel işlem düzeyleri arasındaki farkl111ktır (Köse:2004). 
Bernstein (1990), toplumsal alt sınıflara mensup çocukların ailelerinin kültürel ve dilsel yetersizliklerden dolayı "açık pedagojik pratiğin ardışıklık kurallarının bilişsel gereklerini yerine getiremediklerini ve dolayısıyla, söz konusu egemen pedagojik pratik tarafından bağlam-bağımlı bilişsel bilgi düzeyi ile sınırlı tutularak somut olgular dünyasına mahkûm edildiklerini” ileri sürmektedir (Köse: 2004). Daha kesin bir ifade ile söylemek gerekirse, okul, "bir dizi ayıklama işlemi aracılığıyla, miras yoluyla kültürel sermayeye sahip olanları, bu sermayeden yoksun olanlardan ayırır" (Bourdieu, 1995: 40).

Bernstein'in sözünü ettiği bağlam bağımlı olma ve Bourdieu'nun kültürel sermayeden yoksunluk durumları sözlü kültürle ilişkilidir. Açıktır ki, alt sosyoekonomik toplum kesimlerindeki sözlü kültürün canlılı̆̆ı, düzenlenen eğitsel etkinliklerde dikkate alınmadığı sürece, eğitimin, eşitsizliği sürdüren ve yeniden üreten karakteri tüm katıllğıyla devam edecektir. Dolayısıyla hem söz konusu toplum kesimlerinin yaşam deneyimlerinin hem de bugüne dek öğrenmenin gerçekleştiği sosyo-kültürel çevreye yeterli düzeyde ilgi gösterilmemesinden kaynaklanan sinırllıklar için sözlü kültür incelemeleri bir imkan olarak düşünülebilir. $\mathrm{Bu}$ anlamda sözlü kültür araştırmalarının eğitim alanında süren tartışmalara açılım sağlayabilecek pek çok bulgusundan bahsedilebilir. Burada sözlü kültür çalışmalarının eğitim alanına olası katkısı, -özellikle yetişkin okuryazarlığı bağlamında- öğrenme atmosferi ve eğitsel materyaller, programlara katılım, öğretim yöntemleri, öğretmen ve öğrenenlerin değerlendirilmesi başlıkları altında tartışılmaktadır.

\section{Sözlü Kültür ve Yetişkin Okuryazarlığı}

\section{1- Öğrenme Atmosferi ve Eğitsel Materyaller}

Okuma yazma çalışmaları için -hatta diğer pek çok eğitim programı için- hedef grubun yaşam deneyimleri ve bu deneyimleri nasıl algıladıkları uygulanacak programa uygun bir başlangıç noktası oluşturabilir. Çünkü öğrenenler öğrenme ortamlarına belirli bir deneyim ile birlikte katılır. Özellikle yetişkin öğrenmesi açısından bu birikimin görmezden gelinmesi ciddi problemlere neden olabilir. Sözlü kültürü yaşatan toplum kesimleri açısından bu birikimin öğrenme ortamlarında değerlendirilmesinin iki temel etkisinden bahsedilebilir: Birincisi, sözlü kültürlerde bilgi insan yaşamına yakındır ve soyut olmaktan ziyade duruma bağlıdır. Bu nedenle öğretimdeki içeriğin öğrenenin yaşamı ile ilişkilendirilmesi öğrenme süreci açısından elzemdir. Vurgulamak gerekir ki, öğrenenlerin deneyimlerinin işe koşulması zengin bir öğrenme ortamı yaratmanın önemli bir ayağını oluşturur. İkincisi ise, benlik algısı ile ilişkilidir, yani öğrenenler birikim/deneyim açısından "boş" kabul edildiğinde öğrenme ortamı öğrenenleri dışlayıcı bir havaya bürünür. $\mathrm{Bu}$ açıdan değerlendirildiğinde programın düzenleneceği sosyo-kültürel çevrede bulunan sözlü kültür ürünleri, programa katılanların inanışları, değerleri ve davranış kalıpları hakkında gerçek bir bilgi kaynağı oluşturabilir. 
Genel olarak çocukların ve gençlerin öğrenmesi daha çok konu odaklı iken yetişkinlerin öğrenmesi daha çok sorun ve yaşam odaklı olduğu kabul edilir. Dolayısıyla, yetişkin okuma-yazma programlarında, o programa katılan yetişkinlerin gündelik yaşamlarında kullandıkları tümceler ve sözcüklerin kullanılması; aritmetik öğretilirken yetişkinlerin günlük yaşamlarında karşılaştıkları hesap işlerinin öne çıkarılması yetişkinlerin öğrenmesini kolaylaştırır (Duman, 1999:124). Bu anlamda, okuryazarlık anlayışı sözellikten (orality) ve onun bugün yaşantımızda süren varlığının tanınmasından başlamalıdır (Meek,1991: 15). Freire (1998) de sözlü kültür ürünlerinin yetişkin eğitimi açısından önemini vurgulamıştır. Ona göre, halk öyküleri, bugün de başat olarak sözel bir belleğe sahip olan kültürlerde kuşaktan kuşağa geçer ve kuşkusuz eğitbilimsel rolleri vardır. Bu kültürlerde eğitimin kuramsal boyutu biraz da, halk dilinin zenginliklerinden biri olan eğretilemenin kullanıldığı bu öyküler yoluyla gerçekleşir. Yetişkin eğitimi bu öykülere yabancı kalamaz. Bunlar yalnızca egemen ideolojiyi değil, onunla karışmış olarak, halkın dünya görüşlerine ilişkin görünümleri de yansitır. Bu tür sözlü kültür ürünlerinin eğitsel çalı̧̧malar için nasıl kullanılabileceğini Freire (1998:124) çarpıcı bir biçimde betimler:

(...) Kütüphaneciler, belgeleyiciler, eğitimciler ve tarihçiler tarafindan bir kırsal alanda geliştirilen mükemmel bir proje, kayda alınan görüş̧meler aracıllğıyla bölgenin tarihine ilişkin bir tarama olabilirdi; bu araştırmada bölgenin yaşlı sakinleri çağdaş tanıklar olarak, kendi ortak tarihlerinin temel anları üzerinde odaklaşabilirlerdi. Kısa zamanda bölgenin tarihinin yaşayan bir parçasını oluşturan çok büyük sayıda öykülere sahip olunurdu (Bunun gibi bir çalışmanın Tanzanya ve Gine-Bissau'da gerçekleştirildiğini gördüm). Ünlü halk figürlerine, toplumsal önemiyle köyün “deli”sine, batıl inanışlara, inançlara, sağaltıcı bitkilere, bir tıp doktoruna, büyücülere ve ebelere ve halk ozanlarına dair anlatılar olurdu. Yine bölgenin sanatkarlarıla: Örneğin çamur ya da tahta ile çalışan kukla bebek yapıcılarıyla, heykeltıraşlarla, dantel işleyicilerle ve yaralı kalpleri ya da acaip hastalıkları sağaltan üfürükçülerle yapılmış görüşmeler olurdu. $\mathrm{Bu}$ materyal bolluğuyla, görüşülen kişilerin dilini (söz dizimini, anlamını, vezin tekniğini) kullanan broşürler yayımlanabilirdi. Bu broşürler ve bant kayıtları hem kütüphanelerin kendisinde kullanılabilir hem de bölgedeki diğer etkinlikler için olduğu gibi, okuma-yazma ve okuma-yazma sonrası kurslar için değeri tartışılmaz olurdu. (...)

Freire'in (1998) de belirttiği üzere, böylesi bir projenin sayılamayacak kadar olumlu yönlerinden birisi, hiç kuşkusuz, insanların onları daha iyi tanımaya girişen bir araştırmanın özneleri olma hakkının temelden kabulüdür.

Okuma yazma çalışmalarında, katılanların bilgisinin değersizleştirilmesi / yok sayılması ve dolayısıyla okumaz-yazmazların deneyimlerinin göz ardı edilmesi, okuma-yazma çalışmaları için bir "ölü doğum" olarak değerlendirilebilir. Belki söylemek bile gereksiz, sözünü ettiğimiz şey, katılanların yaşam deneyimlerini 
"yüceltmek" ve onların bu deneyimlerini aynı biçimde yeniden üretmelerine katkı sağlamak değildir. Başka bir deyişle, eğitimciler açısından önemli olan, bu deneyimlerin gerçekleştirilecek programa sunacağı katkının değerlendirilmesidir. Eğitim aracılığı ile bu deneyimlerin dönüştürülmesinin yolu onları yok saymak değil, tersine, bunları yaşatanların bizzat bu deneyimlerle yüzleşmelerini sağlayacak eğitsel ortamların kurulması ve eleştirel bilincin gelişmesini sağlamaktan geçer.

Söz konusu eğitim ortamları için, başta kitaplar olmak üzere, pek çok eğitsel materyal önem taşır. Oysa bugüne dek, çok sayıda araştırmacının da vurguladığ 1 gibi, yetişkinlere dönük okuma yazma kurslarında kullanılan materyallerde özellikle kitaplarda- yetişkinlerin yaşamlarından kopuk konular işlenmiş ve öğrenenlerin yaşadıkları toplumsal çevreyi dikkate alan bir uygulama olarak ele alınmamıştır (Nohl ve Sayılan 2004; Günlü, 2005). Merkezi olarak hazırlanan programlar ve materyallerin tüm kurslarda kullanılarak çeşitli toplum kesimlerindeki farklıııları (Köy-kent, kadın-erkek, genç-yaşlı vb gibi) dikkate almaması, yerel düzeyde zengin öğrenme kaynaklarının kullanılmasını engellemektedir. Oysa Ong'un (1999) da ifade ettiği gibi, sözlü kültürlerin insan yaşamına yakın olması yani, bilgiyle yaşantı arasına mesafe, ancak "yazıyla üretilen ayrıntıll çözümlemeli kategorilerle girmesi"; böyle bir araçtan yoksun sözlü kültürlerde ise, "tüm bilgilerini insan yaşamına dayanarak, yabancı ve nesnel dünyay kendilerine yabancı olmayan insan etkileşimi çerçevesinde özümleyerek kavramlaştırmak" ve söze dökmek zorundalığı (Ong, 1999: 59), özellikle yetişkinler için düzenlenen okuma yazma materyallerinin onların yaşamlarını yansıtabilmesinin önemini apaçık göstermektedir.

\section{2- Programa katılım}

Sözlü kültür incelemeleri, toplumun okul ve öğrenmeye ilişkin algısı ile birlikte katılmaya ilişkin de ciddi veriler sunar. Bilindiği gibi, Türkiye toplumunda, özellikle geleneksel ilişki ağlarının yoğunluğunu sürdürdüğü yerlerde, 'eğitim', 'öğrenme', 'okula gitme' ve 'kitap okuma' gibi kavramlar, çocuklar ya da gençleri çağrıştıırır. Bu kavramların herhangi bir yetişkin için kullanılması, bir eksiklik veya arızi bir durum olarak değerlendirilir. Elbette yetişkinler öğrenmeye devam ederler, ancak bu öğrenme, sınıf ortamında değil, gündelik yaşam döngüsünde, belli etkileşimler içinde gerçekleşir. Okumaz-yazmazlarla yapılan uygulamalarda, bu durum kendini açıkça hissettirir. Pek çok okumaz-yazmaz yetişkin, sınıf ortamında ders görmenin, kendilerini küçük düşüreceğini, yani sınıfin yetişkin olma hakkını elinden alarak onları çocuklaştıracağını ve yalnızca çocukların okulda ders göreceğini düşünmektedir. Bu düşünce biçimi kişinin içinde yer aldığ kültürel çevrenin eğitime bakışını açık bir şekilde yansıtmaktadır. Bu algılama biçimi geleneksel ilişkilerin sürdüğü ve sözlü kültürün hala canlı olduğu toplumsal kesimlerde sıklıkla görülmektedir. Çünkü sözlü kültürlerde, tıpkı modern öncesi toplumlarda olduğu gibi, okul tarzı öğrenme ortamları çocuklara dönük olarak algılanır ve yetişkinlerin yeni beceri öğrenmesi bu tür bir sınıfta, biçimsel öğrenmelerle değil bizzat gündelik yaşamda gerçekleşir. Günümüzün modern 
yaşamında işbölümünün derinleşmesi ve uzmanlaşmanın artması kaçınılmaz olarak okul/sınıf merkezli biçimsel öğrenme ortamlarını yaratmaktadır. Dolayısıyla, sözlü kültürlerin mirasçısı bu toplumsal düşünce formları ile "modern" yaşamın gerekleri arasında bir gerilim kaçınılmaz olarak ortaya çıkmaktadır. Sözü edilen modern ve geleneksel toplumlardaki eğitimin farklı biçimlerde uygulanmasından kaynaklı gerilim Pierce'nin (2003:170-171) çalışmasında açıkça görülmektedir. Pierce (2003), 1960'lı yılların başında Anadolu'da bir köyde gerçekleştirdiği çalışmasında, köye okulun gelmesinden önce sosyalleşmenin -erkekler arasında- yani köy kültürünün değerlerini ve toplumdaki erkeklik rolünü nasıl yerine getireceklerini öğrendikleri yerin, muhtarın evindeki akşam toplantıları olduğunu belirtir. Kuşkusuz bunlar çocuğa özellikle öğretilmiyordu, ancak yetişkinler kendi sorunlarından veya köyün sorunlarından söz ederlerken, bir çeşit zihinsel aktarım yoluyla çocuk, bilgi ve fikir sahibi oluyordu. Amin'in (1997:199) belirttiği üzere, prekapitalist toplumlarda eğitimin biçimsel bir karakteri olduğu genellikle kabul edilir. Yazılı bir dile sahip toplumlarda dil eğitimi küçük bir azınlıkla sınırlıdır ve eğitim, esas olarak, dil, gramer, din ve ahlak öğretmekle uğraşır. Bu da, dini ideoloji türünde bir genel kültürün edinilmesini içerir. Üreticilerin eğitimi ise biçimsel bir kamu eğitim kuruluşunca sağlanmaz. Bu, pratik çalışma deneyimi içinde edinilir.

Geleneksel toplumlardaki eğitimin daha çok gündelik yaşam içinde gerçekleşmesine karşllık, modern toplumlarda öğrenenlerin "modern kurumlar içine kapatılma"sı, modern bir çağda yaşayan ama geleneksel (verbomotor) bir yaşam tarzı süren kesimler için eğitime katılım ciddi bir sorundur.

Programlara katılanlar ile katılmayanların özelliklerini karşılaştırmalı olarak ele alan pek çok eğitim araştırması, özellikle yetişkin eğitimi alanında gerçekleştirilmiştir, çünkü yetişkin eğitimcileri ihtiyaçları ve ilgi alanları çok değişik gruplarla karşı karşıyadırlar (Tekin, 1990). Bu araştırmalara, yani potansiyel hedef kitlenin kestirilmesi ile kitlenin özelliklerinin saptanmasında ve bu kitle tarafindan duyulan ve duyulmayan gereksinimlerin (Miser, 2000: 31) tanımlanmasında yukarıda sözü edilen sözlü kültür araştırma bulgularının önemli katkısı olacağı açıktır.

\section{3- Öğretim yöntemi}

Sözlü kültürün canlılığ1 eğitimin diğer pek çok alanında da kendini gösterir. Eğitim sorunları dile getirildiğinde, sorunlar skalasında ön sıralarda kendine yer bulan "ezberci eğitim", sözlü kültürün eğitime en önemli yansımasıdır. Elbette bu durum yalnızca Türkiye toplumuna ait değildir. Goody, 1968 yılında yayımladı̆̆ 1 "Literacy in Traditional Societies" kitabında bir yazılı kültürün bugün sözlü geleneğe ne derece bağımlı olduğunu zihindeki bellek yükünden, başka bir deyişle eğitimin gerektirdiği ezber oranından belirlenebileceğini ifade eder. Ong'un (1967: 53) da işaret ettiği gibi, Batı'da birkaç nesil öncesine dek ve belki günümüzde de dünyanın pek çok yerinde örgün eğitim, öğrencilerin sınıfta bilgilerini ezberden 
söylemesi, ders kitaplarından ezberledikleri bilgilerle öğretmenin sözlerini desteklemesini (ki bu da kalıp ifade ve sözlü kültür mirasına dayanır) öngörüyordu.

Geleneksel eğitimde ve özellikle dini eğitimde ezberci pratik daha baskındır. Tarihsel olarak bunun pek çok uygulamasından söz edilebilir. Örneğin Akyüz (1993), Osmanlılardaki eğitim-öğretim yöntemini esas olarak "nakilci ve ezberci" olarak nitelendirir. Benzer şekilde, Zengin (2002) ve Unat (1964) medrese eğitiminde, bilgilerin Aristo mantı̆ıına göre şerh ve tefsir edilerek anlamdan çok lafza klymet verilmesi nedeniyle medrese ögretiminin kisir ve verimsiz olduğunu savunmuşlardır. Bugün Kuran kurslarında yapılan eğitimin içeriği ve yöntemi de bir bakıma bu mirası devralmıştır. Bu kurslarda öğrenenlerin, etkili olabilmesi için, bir duanın veya Kuran'ın ayetlerinin doğru bir biçimde ve yalnızca Arapça tekrar edilmesi gerektiğine inanması, Kuran'ın ayetlerinin anlamını bilmeden Arapça ezberlenmesine yol açmaktadır. Ancak ezberci eğitim anlayışının sürdüğü yegâne yer kuran kursları değildir. İlköğretim okullarından lisans-üstü eğitime kadar tüm eğitim kademelerinde "tekrara ve ders notlarının ezberlenmesi"ne dayalı uygulamalar devam etmektedir. Szyliowicz (2003:416)'in çarpıcı ifadesiyle, "günümüz üniversite sinıflarının birçoğunda, bir Osmanlı müderrisinin yabancllık çekeceği” bir pedagojik ortam bulunmamaktadır.

$\mathrm{Bu}$ tür ezberci pratikler için, Ong'un betimlemesi açıklayıcıdır: Sözlü kültürlerde, çıraklık, bir tür çıraklık sayılan müritlik, dinleme, dinlenileni tekrarlama, atasözlerine ve bunları yeniden tertiplemeye hakim olma veya kalıplaşmış deyişlerle özgün deyişler oluşturma temel öğretim yöntemleridir (Ong, 1999:21). Sözlü kültürlerde zeka, genellikle vecize bulmaktaki yaratıcılıkta, yani geniş kapsamda uygulanabilecek sözlü deyişler bulma gücüyle birlikte anılmaktadır (Postman, 1994: 34):

İlk Krallar'da öğrendiğimiz Akıllı Solomon yaklaşık üç bin atasözü biliyordu örneğin. Basılı söze dayalı bir kültürde ise aynı yeteneğe sahip kişilerin en iyi ihtimalle garip insanlar, daha çok da gururlu baş belaları oldukları düşünülür. Salt söze dayalı bir kültürde, ezberleme yetisine her zaman büyük değer verilir, zira yazılı sözlerin bulunmadığı yerlerde insan zihni ayaklı bir kütüphane gibi işlemek zorundadır. (...) Basılı söze dayalı bir kültürde ise bir şiirin, bir menünün, bir yasanın ya da çoğu şeyin ezberlenmesi yalnızca etkileyicidir; o kadar.

Sözlü kültür çalışmaları bağlamında okuma yazma öğretim yöntemlerini de yeniden düşünmek anlamlıdır. Bilindiği gibi, bu yöntemler "sentez", "analiz" ve "karma" yöntemler olarak üç ana grupta toplanmaktadır. Sentez yöntemler harf, ses, bak-söyle vb yöntemlerden oluşmaktadır. Bu yöntemlerde ağırlıklı olarak parçadan bütüne gidilmektedir. Analiz yöntemler, kelime, cümle, cümlecik ve hikaye yöntemlerinden oluşur. Karma yöntemler ise bu iki yöntemin karıştırılmasından oluşan yöntemlerdir (Güneş, 2005:136-137). Okuryazarlık ile ilgili eğitim literatürü incelendiğinde, bu yöntemlerin hangisinin ve neden daha iyi olduğuna dair yoğun 
araştırmaların/tartışmaların olduğu görülür. Bu tartışmaların kapladığı alan göz önünde bulundurulduğunda, okuryazarlıkla ilgili en önemli sorunun, sanki söz konusu öğretim yöntemlerinden birine karar vermek sorunu olduğu anlaşllabilir. Elbette okuma-yazma öğretim yöntemi önemlidir, ancak, hangi yöntem kullanılırsa kullanılsın okuma yazma öğretmenin olanaklı olduğu ve her yöntemin çeşitli avantajları ve dezavantajları olduğu bilinmektedir. Öyle ki, Scribner ve Cole (1988: 63) tarafindan yapılan bir araştırma sistematik bir yöntem uygulanmadan da okumayazmanın öğretilebileceğini göstermektedir. (Liberya'da yaşayan Vai'ler resmi eğitim örgütlenmesi dışında, 'okulsuz okuryazarlık' anlayışı diyebileceğimiz bir şekilde Vai yazısını, öğretmen olarak bir arkadaş ya da akrabanın yardımıyla öğrenmektedirler). Bu nedenle, sözlü kültür incelemelerinin işaret ettiği gibi, üstünde durulması gereken asıl nokta -en az okuma yazma yöntemi kadartoplumun eğitime/okuryazarlığa verdiği değer, anlam ve işlev olmalıdır.

\section{4- Öğretmenlerin ve öğrenenlerin değerlendirilmesi}

Sözlü kültür incelemeleri/ürünleri geleneksel ilişkilerin güçlü olduğu topluluklardaki bilgi edinim, kullanım ve aktarım süreçlerine dair açıklayıcı bilgiler sunar. Ong, sözlü kültürlerin, kavramları duruma göre, işlevsel ilişki çerçevesinde kullandığını, bu çerçeve de canlı insan yaşamına yakın olduğu için kavramların soyutluğunun asgari olduğunu iddia eder. Bu görüşlerini de Luria'nın çalışmaları ile temellendirir.

Luria (1976), 1931-1932 yıllarında Sovyetler Birliği'nin Özbekistan ve Kırgızistan bölgelerinin ücra köşelerindeki hiç okuma-yazma bilmeyen ve biraz okuma-yazma bilenler üzerine bir araştırma yapmıştır. Luria ve yardımcıları, söyleşiye katılan deneklere bildikleri bilmecelerle başlayarak sorular sormuş ve verilerini bu uzun söyleşilerden derlemişlerdir. Deneklere üçü aynı kategoriye ait dört nesnenin resmi gösterilip tek grupta toplanabilecekleri bir araya getirmeleri istenmiş̧ir. Söz konusu dizilerden birisi, çekiç, testere, kütük ve el baltası'nın resimlerinden oluşur. Okuryazar olmayanlar, bu grubu kategorik (üç alet ve bir alet olmayan: Kütük) olarak düşünmeye ısrarla yanaşmamış, gruba pratik açıdan "duruma göre düşünerek"- yaklaşmış ve israrla nesneleri birbirinden ayırmak istememişlerdir. 25 yaşındaki okuryazar olmayan bir köylünün yanıtı şöyledir: "Hepsi bir. Testere kütü̆̈̈̈ keser, balta ufak parçalara böler. Bunlardan birini ayırmam gerekse, baltadan vazgeçerim; nasıl olsa testere kadar yararlı değil" (1976: 56). Çekiç, balta ve testerenin aletler grubunu oluşturduğu işaret edilince köylü, bu sinıflandırmayı reddedip kendi durumuna göre düşünmeye devam eder; "Evet, ama aletim olsa da aletimi kullanacak kereste yoksa alet ne işe yarar ki". (Akt: Ong, 1999).

Luria'nın bir başka sorusu: Karla kaplı kuzeyde bütün ayılar beyazdır. Novaya Zembla Kuzeyde ve karlidir. Ayllar ne renk olur? Yantlar: "Ne bileyim. Ben hep kara ayl gördüm: Başka renk ayı görmedim... Her yerin aylsı başka türlüdür." Aynı soru güçlükle okuyup yazan 45 yaşındaki bir kolhoz işçisine ikinci kez 
sorulduğunda yanıtı şudur: "Sizin sözlerinize bakılırsa, tüm ayıların beyaz olması gerek".

Luria'nın araştırmasında, en somut nesnelerin bile tanımlanması isteğine karşı gelinmiştir. "Ağaç nedir? Açıklamaya çalışın." 22 yaşındaki okur-yazar olmayan köylünün tepkisi, "Ne gerek var ki? Herkes ağaç nedir bilir, benim söylememe hacet yok" biçimindedir. "Íki kelime ile ağacı nasıl tanımlarsın?" sorusuna yanıt ise şöyle verilmiştir: "İki kelimeyle mi? Elma ă̆acı, karaağaç, kavak."

Dikkat edilirse, özellikle Luria'nın araştırmasında sorulan sorular, metin kullanmasını bilenler için ders sorularıdır ve okuryazarların hazırladıkları zeka testlerine benzemektedir. Kendi içlerinde geçerli olabilirler, ancak sözlü kültür insanının paylaşmadığı bir dünyadan gelmektedirler. Oysa sözlü kültür halkı, insan zekasını ders kitaplarından alınmış sorularla değil bir işlem bağlamında değerlendirir. (Ong, 1999: 72-73). Ong, bunu Carrington'un çalışmasındaki bir örnekle gösterir: "Bir orta Afrikalı'nın köy okuluna atanan yeni müdür hakkındaki görüşü sorulunca, araştırmaciya verilen yanıt, 'Hele önce nasıl dans ediyor görelim' biçiminde olmuştur (1974: 61).

Bugün bize sıradan gelen zeka testlerinin, yazı ve matbaanın derinden koşullandırdığı özel bir bilince, "modern bilince" göre hazırlandığını, bu tür testleri önemli bulanların kabul etmeleri gerekir (Akt. Ong, 1999: 73; Berger, 1978). Modern bilince sahip olmayan öğrenenleri, modern kültürün değerlendirme araçlarıyla değerlendirirken daha dikkatli olunmalıdır. Sözlü kültürü paylaşan insanların, modern yazı dünyasına girişte zorlanacakları açıktır.

\section{SONUÇ}

Modernleşme sürecinden kaynaklı olarak Türkiye'de eğitim ve okuryazarlığa ilişkin teknisist bir yaklaşım hakim olmuştur. Eğitimi yerel ve insani gerçekliklerden bağımsız bir olgu biçiminde değerlendiren bu yaklaşım, öğrenenleri de tarihsiz nesneler olarak görür. Oysa günümüz dünyasında, en 'evrensel' alanlardan biri olarak kabul edilen matematik alanı için bile "etno-matematik" (Frankenstein ve Powel, 1994:75) nitelemesi yapılabilmektedir. Yetişkin öğrenmesi açısından da öğrenmenin ve davranışın gerçekleştĭgi sosyal çevreden yalıtılamayacağı (Bélanger ve Blais, 1995: 13-14) vurgusu giderek artmaktadır.

$\mathrm{Bu}$ anlamda sözlü kültür incelemelerinin yetişkin eğitimi alanına, özellikle de yetişkin okuryazarlığı çalışmaları için sunduğu en önemli katkı, bugüne dek ihmal edilen öğrenmenin gerçekleştiği sosyo-kültürel bağlama dair ayrıntılı betimlemeler sağlamış olmasıdır. $\mathrm{Bu}$ anlamda sözlü kültür çalışmaları, eğitim bilimcilerini, eğitimi etkileyen okulun/sınıfın dışındaki etmenleri ele almaya davet eder. $\mathrm{Bu}$ etmenler öğrenenlerin yaşam dünyalarını ya da Bourdieu'nun (1994) ifadesi ile öğrenenlerin "habitus”u ile ilgilidir. Öğrenenler ile öğretmenlerin birbirlerinden tamamen farklı habitusları olduğunda, bu durum çoğunlukla pedagojik kopukluğa yol açar. Özellikle temel yetişkin eğitiminde söz konusu kopukluk daha dramatik 
sonuçlara yol açabilecektir. Freire (1995: 89)'nin "bankacı eğitime karşı" önerdiği "problem tanımlayıcı eğitim"in ilk aşamasının katılanların "konusal evren"inin keşfi olması, öncelikle bu kopukluğun daha baştan önlenmesine dair bir çabadır. Yetişkin eğitimi ve özellikle de yetişkin okuryazarlı̆̆ı programlarında, katılanların yaşam deneyimlerinin ve kendi ifadelerinin seslendirilmelerine firsat tanındığında, öğrenenlerin motivasyonlarının arttığı gözlenebilir bir gerçekliktir.

Sözlü kültürü yaşatan toplum kesimlerinin aynı zamanda dezavantajlı konumda bulunan toplum kesimleri olmaları nedeniyle, toplumsal eşitsizlikleri gidermeye yani dezavantajlı konumda bulunan toplumsal kesimleri güçlendirmeye çalışan eğitim uygulamaları açısından, sözlü kültürün bilgisi yol göstericidir. Eğitimsel eşitsizliklerin giderek derinleştiği günümüzde, bu bilgi daha da önemli hale gelmiş̧ir. Egemen pedagojik pratiklerde, sözlü kültürü yaşatan bireylerin yazılı iletişimin geliştirildiği kurumlardan en önemlilerinden olan okulda zorlandıkları açıktır. Oysa sözlü kültür ürünleri pedagojik uygulamalar için verimli bir kaynak olabilir: Sözlü kültür ürünleri, öğrenenlerin yaşamlarına yakın zengin bir öğrenme ortamı ve materyali yaratmak için gerekli olan malzemeyi sağlar.

Sözlü kültür incelemeleri yetişkinlerin bilgi edinme, saklama ve aktarma biçimlerine dair de ipuçları taşır. Sözlü kültürde bilgi, "bireysel bir deneyim değil, toplumsal bir olgudur; o yüzden kimse bir diğerinden daha aptal ya da daha akzllı sayllmaz". Geleneksel olarak anlatılan söylenceler ve öyküler, çocuklara anlatılan masallar aracılığı ile bilgi, "herkesin çevresinde ayrı ayrı dokunan ortak bir bilinci oluşturur, bilgiye herkesle birlikte" ulaşı1ır (Sanders, 1999: 22).

Sözlü kültürün eğitimsel olana katkısı anlamında, değinilmesi gereken önemli noktalardan biri de öğretmenin rolüdür. Sözlü kültür incelemeleri, öğrenenlerin sosyo-kültürel çevresinin öğrenme etkinliği açısından önemini vurguladığı için, özellikle öğretmenin sorumluluğunu artırır. Buna göre, öğretmen çevrenin sosyokültürel özelliklerini araştırmalı ve bu araştırma sonuçlarına dayalı olarak eğitim etkinliğini sürdürmelidir. Çoğu kez öğretmen de "sözlü kültür”ün bir parçasıdır; dolayısıyla öğretmen sözlü kültüre ilişkin farkındalığını geliştirmeli ve sözlü kültürle ilişkisini nesneleştirebilmelidir. 


\section{KAYNAKLAR}

Akyüz, Y. (1993). Türk Eğitim Tarihi. Kültür Koleji Yayınları, İstanbul.

Amin, S. (1997). Emperyalizm ve Eşitsiz Gelişme. (Çev: Semih Lim). Kaynak Yayınları, İstanbul.

Bélenger, P. ve Blais, M. (1995). World Perspectives in Adult Education Research. Adult Education and Development, 45:5-22.

Berger, B. (1978). "A New Interpretation of the IQ Controversy". The Public Interest, Say1 50 .

Bernstein, B. (1990). Social Class and Pedagogic Discourse: Class, Code, and Control. London: Routledge.

Bourdieu, P. (1994). Language\&Symbolic Power. (Translated by Gino Raymond and Matthew Adamson). Harward University Presss. Cambridge, Massachusetts.

. (1995). Pratik Nedenler. (Çev. Hülya Tufan). Kesit Yayıncılık, İstanbul.

Carrington, J.F. (1974). La Voix des tambours: comment comprende le language tanbourine d'Afrique. Kinshasa: Centre Protestant d'Editions et de Diffusion.

Çobanoğlu, Ö. (2003). Türk Halk Kültüründe Memoratlar ve Halk Inançları. Akçağ Yay. Ankara.

Duman, A. (1999). Yetişkinler Ĕgitimi. Ütopya Yayınevi, Ankara.

Freire, P. (1995). Ezilenlerin Pedagojisi. Çev. (D. Hattatoğlu ve E. Özbek) Ayrıntı Yayınları, İstanbul.

Freire, P. ve Macedo, D (1998). Okuryazarlık, Sözcükleri ve Dünyayı Okuma. (Çev: Serap Ayhan). İmge Kitapevi Yayınları, Ankara.

Frankestein, M. ve Powell, A. (1994). Toward liberatory mathematics: Paulo Freire's epistemology and ethnomathematics. (Ed. McLaren, P. ve Lankshear, C.). Politics of Liberation. Routledge, London ve New York.

Goody, J. (1989). Oral Culture. International Encyclopedia of Communications. Oxford University Press. New York.

(1968). Literacy in Traditional Societies, Giriş: Goody, J. Cambridge,

Cambridge University Press.

(2001). Yabanıl Aklın Evcilleştirilmesi. Dost Kitabevi Yayınları, Ankara.

Göka, E. (1999). Bilimlerin Vicdanı: Psikiyatri. Ütopya yayınları, Ankara. 
Güneş, F. (2005). "Niçin Ses Temelli Cümle Yöntemi?”. Eğitimde Yansımalar: VIII. Yeni İlköğretim Programlarını Değerlendirme Sempozyumu. 14-16 Kasım 2005. Erciyes Üniversitesi, Sabanc1 Kültür Sitesi, Kayseri.

Günlü, S. (2004). Dönemsel değişimler Işı̆ğında Türkiye'de Okuma Yazma Kampanyalarının Değerlendirilmesi. Yayımlanmamış Doktora tezi. A.Ü. Eğitim Bilimleri Enstitüsü.

Kayaoğlu, İ.G. (1998). İstanbul'da Bakırcı, Hurdacı ve Antikacı Esnafinın Ağzı.Pertev Naili Boratav'a Armağan. (Haz. Metin Turan). Kültür Bakanlığı Yay.

Köker, E. (2005). Kitapta Kurutulmuş Çiçekler ya da Sözlü Kültür Üzerinde Düşünmek. Dipnot yayınları, Ankara.

Köse, M.R. (2004). "Basil Bernstein: Pedagojik Pratik Biçimlerinin Toplumsal sınıfsal Kökenleri Üzerine”. Eğitim Bilim Toplum Dergisi, Cil 2, sayı 7.Ankara.

Luria, A.R. (1976). Cognitive Development: Its Cultural and Social Foundations, Der. Michael Cole, Cambridge, Mass ve Londra: Harward University Press.

Ong, W. (1967). The Presence of the Word. Yale University Press.

Ong, W. (1999). Sözlü ve Yazıll Kültür Sözün Teknolojileşmesi. (Çev: Sema Postacıŏlu Banon). Metis Yayınları, İstanbul.

Pierce, E.J. (2003). Bir Türk Köyünde Yaşam. (Çev. Zeycan Sarıhacıoğlu). Epsilon yayınevi, İstanbul.

Postman, N. (1994). Televizyon: Öldüren Eğlence. (Çev: Osman Akınhay). Ayrıntı Yayınları, İstanbul.

Mcluhan, M. (1999). Gutenberg Galaksisi Tipografik Insanın Oluşumu. (Çev: Gül Çağalı Güven). YKY yayınları,İstanbul.

Meek, M. (1991). On Being Literate. The Bodley Head, London.

Miser, R. (2000). Topluluk Katılımı. A.Ü. Eğitim Bilimleri Fakültesi yayınları No, 183. Ankara.

Nohl, A.-M./ Sayllan, F. (2004). Türkiye'de Yetişkinler için Okuma Yazma Eğitimi. Temel Eğitime Destek Projesi Teknik Raporu (Milli Eğitim Bakanlığı/Avrupa Komisyonu), 2004.

Sanders, B. (1999). Öküzün A'sı. Elektronik Çağda Yazılı Kültürün Çöküşü ve Şiddetin Yükselişi. Ayrıntı Yayınları, İstanbul.

Scribner, S.and Cole, M. (1981). The Psychology of Literacy. Cambridge: Harvard University Press. 
Szyliowicz, J. (2003). Osmanlı'nın Eğitsel Mirası: Efsane mi, Yoksa Gerçek mi? Imparatorluk Mirası: Balkanlar'da ve Ortadoğu'da Osmanlı Damgası. Der. Carl Brown. (Çev. Gül Çağalı Güven). İletişim yayınları, İstanbul.

Tannen. D. (1980). "A Comporative analysis of oral narrative strategies: Athenian Greek And American English". The Pear Stories: Cultural, Cognitive, and Linguistic Aspects of Narrative Production içinde. Der: Wallace, L. Chafe Norwood, Nj. Ablex, S.51-87.

Tekin, M. (1990). Yetişkin Eğitiminde Katılma ve İlgili Araştırmalar. A.Ü. Eğitim Bilimleri Fakültesi Dergisi. Cilt: 22, Sayı:2

Unat, F.R. (1964). Türkiye Eğitim Sisteminin gelişsmesine Tarihi Bir Bakış. MEB yay. Ankara.

Zengin, Z. S. (2002). II. Meşrutiyette Medreseler ve Din Eğitimi. Akçağ yayınları. Ankara. 
